\title{
Social Media Marketing as a Branding Strategy in Extraordinary Times: Lessons from the COVID-19 Pandemic
}

\author{
Sanne Ichelle Dubbelink *, Carolina Herrando (D) and Efthymios Constantinides (D)
}

check for updates

Citation: Dubbelink, S.I.; Herrando, C.; Constantinides, E. Social Media Marketing as a Branding Strategy in Extraordinary Times: Lessons from the COVID-19 Pandemic.

Sustainability 2021, 13, 10310. https:/ / doi.org/10.3390/su131810310

Academic Editor: Jose Ramon Saura

Received: 16 August 2021

Accepted: 11 September 2021

Published: 15 September 2021

Publisher's Note: MDPI stays neutral with regard to jurisdictional claims in published maps and institutional affiliations.

Copyright: (c) 2021 by the authors. Licensee MDPI, Basel, Switzerland. This article is an open access article distributed under the terms and conditions of the Creative Commons Attribution (CC BY) license (https:// creativecommons.org/licenses/by/ $4.0 /)$.
Faculty of Behavioural, Management \& Social Sciences, University of Twente, P.O. Box 217, 7500 AE Enschede, The Netherlands; c.herrando@utwente.nl (C.H.); e.constantinides@utwente.nl (E.C.)

* Correspondence: s.i.dubbelink@student.utwente.nl

\begin{abstract}
This review expands our insight into the ways the required adaptation to digital channels caused by COVID-19 has affected the creation of brand equity through social media marketing. Based on a systematic literature review, we propose a conceptual framework that answers the following research question: How can businesses, amidst and after the COVID-19 pandemic, adapt their social media marketing strategy to create positive brand equity? The conceptual framework describes four components as the basis for a potential social media marketing strategy. First, (1) businesses need to develop a clear perspective on their current social media marketing activities, and (2) evaluate current branding elements. Based on this, (3) the timeline of marketing activities must be postponed or adapted to the needs of consumers. Lastly, (4) businesses must adapt their messaging to show empathy and deliver relevant information. Within this process, governmental parties, financial institutions, influencers, and consumers are identified as stakeholders who influence and assist businesses in optimizing their social media marketing strategy. These findings are relevant for academics and businesses to further understand the long-term effects of COVID-19 on social media marketing. Additionally, they highlight that the roles of online channels and the consumer are expanding in the future.
\end{abstract}

Keywords: social media marketing; brand equity; COVID-19; consumer behavior; customer experience

\section{Introduction}

The COVID-19 pandemic has created substantial growth for internet-based businesses as an increasing number of consumers are shopping online [1]. In 2020, the global ecommerce market has seen an increase of $27.6 \%$, surpassing over 4.28 trillion US dollars [2]. In the past few years, organizations have been subject to the introduction of digital technologies that transform organizations, interactions with consumers, and the creation of value [3-5]. Online shopping has created the opportunity to compare products more conveniently and consumers can easily choose the products that fit their needs the most [6]. Mostly young consumers have shifted to online spending, affecting the manner in which businesses have to operate as young consumers are more likely to shop through social media [7]. Additionally, $62 \%$ base their purchase decisions on the impact that these have on society, e.g., sustainable and green products, in comparison to 53\% of middle-aged consumers and $44 \%$ of older consumers [7].

Subsequently, as more consumers and businesses are adapting to buying and selling through online channels, the digital marketing sphere is becoming more competitive [8]. When looking at the state of digital marketing amidst the COVID-19 pandemic, a special emphasis should be put on Social Media Marketing (SMM) as it offers a wide range of tools to target customers more effectively. Social media has also become a large influence on online shopping, as research shows that $54 \%$ of purchases made by younger consumers are from independent retailers they discovered via social media [7]; this is $43 \%$ for middle-aged consumers and $25 \%$ for older consumers. This is especially promising as social media has 
become a primary communication channel for many and the time consumers spent online has drastically increased since the start of the pandemic [1,9]. As SMM is aimed at the creation of interactions with consumers in the digital settings where they already spend time, businesses can enhance their customer experience by analyzing customers and their conversations [10].

As social media has become a user-centered sphere where consumers gather information, communicate with other consumers, and share their opinion, businesses aiming to sell their products are viewed as unwelcome [11]. Therefore, in order to last in the competitive online market, businesses must effectively work towards creating positive brand equity $[1,12]$. However, it remains unclear how the COVID-19 pandemic has affected the way businesses must create long-term brand equity through SMM, while simultaneously needing to quickly adapt to rapid changes and increased competitiveness within digital channels. Additionally, communicating the benefits of a brand and measuring brand equity properly remains rather difficult for many businesses [13] and within current research, an emphasis is often put on consumer-centered behavior, e.g., buying behavior, consumer decision-making, and the consequences for businesses. Topics such as impulsive purchases, hoarding behavior, changing brand perceptions, the do-it-yourself mentality, and the shift to online working, studying, and shopping are very prevalent in literature $[6,9,14,15]$. Rather than the perspective of the consumer, this research expands on the perspective of businesses that are forced to rapidly adapt to changes in the online sphere and consumer behavior with the goal of creating brand equity. Existing research regarding the effects of the COVID-19 on businesses has identified some reasons that might affect the manner in which businesses and consumers create brand equity online. These reasons demonstrate the importance of researching and identifying possible long-term effects and changes in brand strategies in the context of brand equity that have not been seen in this extent pre-COVID-19.

The first factor is the digitalization of business practices, requiring many to work from home. This is suggested to affect the way organizations and consumers function. External digital knowledge sharing through organizations, i.e., with consumers and external experts, is negatively affected as working from home creates employees' perception of social distance from the company [16]. Consumers are also affected by the digitalization of business practices as they are more hesitant to adopt mobile payment services when consumers experience misalignment with their current schedules or habits, negative stereotypes, privacy concerns, and lacking visibility in society [17]. In accordance, those who are satisfied with digital services seem to buy more frequently and in larger quantities [18]. This might indicate that when businesses are not able to communicate the developments regarding their digital channels and how these can assist consumers, consumers might be less likely to purchase products and services from these businesses.

Additionally, the second factor is the importance of brand engagement on social media with the goal of generating brand equity, as brand engagement on social media gives businesses the opportunity to directly communicate and interact with consumers [19]. The importance of building an online presence has increased during the pandemic and building a positive brand perception through different forms of customer engagement can help businesses create online brand equity [20]. This is more important than ever in a time where consumers spend a considerably larger amount of time online and positive past brand-based SMM experiences that provide consumers with cognitive, social, and personal benefits positively influence the perceived brand equity $[20,21]$.

A third additional factor that influences the context of this research is finances, as the financial situation of many consumers and businesses has changed drastically during the pandemic. Research shows that the stocks of those who focus on enhancing brand equity are to a lesser extent affected by the pandemic crash [22]. Those who are informed on and participate in debates and news on finances are more likely to perform activities in relation to buying and selling products in situations like COVID-19 [23]. Additionally, it is suggested that consumers look to the recommendations and behavior of others and make 
decisions in accordance with others [23]. This indicates that knowledge and awareness of what others are doing is an important factor in how both businesses and consumers make financial choices. This might affect the way they buy and sell products through online channels, hence highlighting the importance of researching the effects of e-commerce on social media marketing in times of the COVID-19 pandemic.

Considering the aforementioned, this study aims to answer the following research question: How can businesses, amidst and after the COVID-19 pandemic, adapt their social media marketing strategy to create positive brand equity? This research question will be answered through a systematic literature review and the development of a conceptual framework. With this, we outline a brief strategy and relevant stakeholders that can assist businesses in building a foundation for their SMM strategy that is adapted to changing technologies, consumer behavior, and markets as a result of the pandemic. These results also function as a building block for future research regarding the creation of brand equity in the digital marketing sphere. First, we will discuss the main topics defining the research domain, followed by the methodology explaining the process of data collection. The results will emphasize the value of brand equity in today's SMM sphere, followed by the identification of relevant stakeholders and steps that businesses can take to adapt their SMM strategy to current times.

\section{Theoretical Framework}

\subsection{Social Media Marketing as a Part of the Marketing Strategy}

Social media is defined as "Web 2.0 applications enabling the creation, editing and dissemination of user-generated content" [24] (p. 42). Web 2.0 can be seen as a technical structure to share media with others and create consumer-generated content [25]. Dahnil et al. (p. 120) define the construct of SMM as "a new field and a new business practice involved with the marketing of goods, services, information and ideas via the online social media" [26], which is used to interact with customers, find key consumer influences, create engagement, and find brand ambassadors [27]. Social media offers users an increased number of opportunities for online participation, as this participation can take place anywhere and is not linked to a physical meeting [28]. Furthermore, new digital technologies provide benefits such as convenience, enjoyment, richness of information, and saving time and money, which are appreciated by consumers [29].

Constantinides (2014) proposes the E-Marketing Pyramid model, consisting of four different levels illustrating the relationship between SMM and other parts of the marketing strategy [24]. The first level, the product and service, marks the importance of product or service quality and brand image, which should be thoroughly integrated in the organization. The second level is the marketing organization, which further specifies the communication regarding brand value and the market-oriented character of an organization in order to adapt to traditional and online marketing activities. Dahnil et al. (2014) found that the end users, the organizational structure, technological resources, management, and the business environment of a business affect the likelihood of adopting SMM [26]. The third level, the Web 1.0, lays down the fundamentals for the implementation of SMM and specifies the importance of an excellent web presence [24]. A website needs to have a high appeal, as this directly influences the customer experience and is necessary to convince the critical online customer [30]. The fourth level is Web 2.0, where SMM is implemented based on sufficient preparation in previous levels to create a strong foundation. Within this level, it is important to critically evaluate formulated objectives and the internal capabilities to create an effective strategy [24].

\subsection{The Empowered Social Media Consumer}

The introduction of social media as communicative platforms for consumers to interact with or about brands has drastically changed the relationships between brands and consumers. The consumer is now more powerful in the social media environment that was designed with the purpose to accommodate consumers rather than businesses [11]; this has 
created obstacles for businesses to interfere in this environment where they are considered uninvited to the conversation [11]. According to Hwang et al. (2021), the manner in which consumers adopt social media to gather information and make purchase decisions is affected by three dimensions of gratifications: process, content, and social gratification [31]. Progress gratification refers to the gratification in the use of social media and the information supplied on social media platforms. The content gratification specifically examines the gratification that individuals experience when viewing the content on social media. Lastly, social gratification refers to opportunities to interact with other users through social media platforms and the extent to which it fulfils the need for social interactions. These forms of gratification positively affect the adoption of social media as a source of information to make purchase decisions; social media decreases risks through providing information in larger quantities than other platforms and the presence of social feedback, e.g., reviews and descriptions provided by others, which assist users in finding the information needed to make a decision [31]. This has empowered the consumer as social media offers them the possibility to educate themselves and each other, enhances their power to choose what they prefer from available options, and organize themselves as consumers in favor or against a specific brand or event [32]. To make sense of the manner in which functionalities shape the social media environment, Kietzmann et al. (2011) identified seven functionalities which all examine an element of the social media user experience and its implications for businesses aiming to build a community on these platforms (Figure 1) [33].

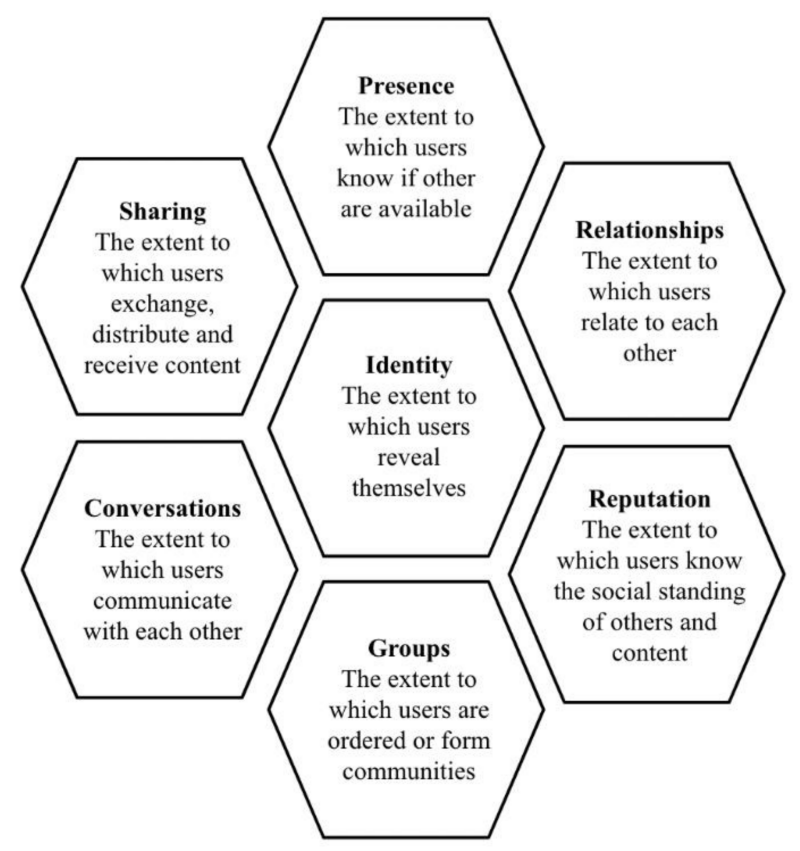

Figure 1. The Seven Functional Blocks of Social Media, as visualized by Kietzmann et al. (2011).

The first functionality of social media is the identity displayed by users, referring to the extent in which they expose their identities within social media settings [33]. This refers to objective information regarding identity, e.g., name and gender, but also aims to represent a broader spectrum of subjective identities rooted in different types of self-expression, e.g., thoughts, feelings, and likes [33]. Online self-disclosure increases user satisfaction but can become problematic when the user spends extensive amounts of time online to stay informed about the engagement they receive from their social circle [34]. Regardless, as consumers willingly share their identities online, they are still protective over their information [33]. Therefore, businesses must pay attention to the privacy of consumers when aiming to communicate with them or analyze consumer segments to optimize their marketing practices [33]. 
As consumers communicate their identities, they also hold conversations with other users and groups, forming the second functionality of social media [33]. Users have different goals within the conversational use of social media; they either have a specific goal, e.g., meeting like-minded people, or a broader goal, e.g., making an impact in debates on current issues [33]. When people are able to share overlaps in their identity with others through conversation, this will increase the opportunities for self-expression, enhancing their motivation to participate in discussions and movements important to them [35]. When attempting to interfere in conversations, businesses first must take into account the content and frequency of content publication among users in order to understand the "conversation velocity"; the change of conversation in terms of rate and direction in which they change [33]. Then they must be knowledgeable about when to manipulate conversations held by consumers; brands that know when to partake or to not partake in the conversation will give consumers the perception of a caring brand that is a positive addition to the existing conversation [33].

The extent to which individuals exchange, distribute, and receive content is referred to as sharing, the third functionality of social media [33]; social media connects people over a shared object and functions as a form of interaction that can result in conversing or building relationships [33]. Social media not only offers its users the opportunity to provide companies with feedback in an interactive, fast, and flexible environment, but also allows them to share their brand journey with other users [36]. Being part of a community enhances the likelihood of members to share meaningful beliefs and lifestyles, as the relationships that emerge are valued over consumerism or the ownership of tangible goods [35]. Based on this, businesses must identify (1) what objects the users have in common to identify new objects they can relate over and (2) to what extent this object can or should be shared, e.g., in terms of copyright infringements [33].

The fourth functionality, referred to as presence, describes the extent to which users are knowledgeable of the presence of other users [33]. Inherently, the factor of presence is closely tied to other functionalities such as conversations and relationships; businesses need to take into account the importance of user presence and location and adapt their communication style to the manner in which consumers engage with one another [33]. Peer reviews, which represent the presence and experiences of other consumers in the context of e-commerce, have a significant, positive effect on the evaluation and purchase intention of products or services [37]; this effect is enhanced when reviews provided by those in close relationship to the consumer are also present [37].

The fifth functionality of social media, forming relationships, is defined by the association between users, leading them to converse, share content, meet each other or listing them as a friend [33]; how these users define their connection also defines the content exchange with one another. Users can either form groups within their social network or through groups that connect through their experiences or interests regarding a certain topic [33]. Virtual connections assist users in finding niche groups to which they can belong within a wider online community [11]. Therefore, firms must understand how they can build or maintain relationships with consumers when attempting to engage with them.

Reputation is categorized as the sixth functionality and a determining factor in deciding the standing of the self and others within the realm of social media; the trust in others, their expertise, and their content are often leading in social media environments, although the technologies are not yet sufficient at assessing the trustworthiness of content [33]. Within the realm of Web 2.0, reputation is seen as the currency in which businesses deal to position themselves and the role of PR is becoming increasingly important in managing reputation [11]. Accordingly, brand reputation among users must be measured through a preferred metric that fits these factors and that is identified by the business, together with a corresponding evaluation tool in order to determine the exact reputation [33].

The seventh and final functionality is the formation of groups [33]. When users form groups, it is beneficial to allow these communities to label users as members or non-member relations without these members knowing in order to further pursue their agenda, grow 
the membership etc. [33]. Apart from the initial goal, as set by the group, groups can also offer individuals secondary benefits that benefit their well-being, such as recognition, valuable social contacts, and the sense of belonging to something that is larger than just the group in question [35]. Businesses need to be aware of the fact that groups are not just a certain number of users, but that they function as independent segments within the realm of social media, including their own rules and structures [33].

\subsection{Adopting Social Media as a Part of the Business Practice}

In order to create a further understanding of how businesses can adopt social media to communicate with consumers, a framework has been developed by Jacobs and Nakata (2010) (Figure 2) [38]. This framework, which is based on the earlier model developed by Earl (2000), emphasizes the importance of external communication about the brand with consumers as the first step in adopting social media [30]. As social media is where consumers currently much spend time, they expect brands to be present as well [39]. One of the abilities of social media is offering consumers the ability to narrow down the available options and simplify the decision-making process, increasing consumer well-being and their quality of life [32]. However, this remains rather difficult as web 2.0 technologies are rather divers, consisting of many categories, e.g., blogs, social networking sites, and wikis [38]. The factor of responsibility for the business to use social media is seen as the problem due to the diverse set of tools, the ease at which something can be used and created, and the lack of a clear strategy [38].

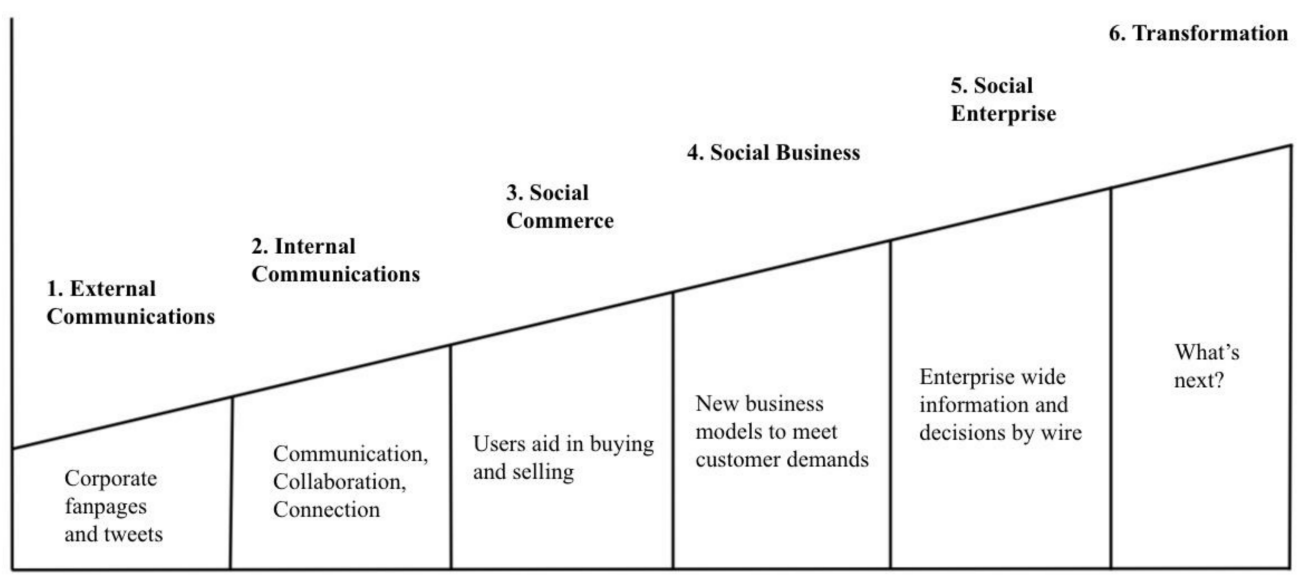

Figure 2. The Stages of Growth Model Derived from Earl's Model, as visualized by Jacobs and Nakata (2010).

Therefore, it is suggested that, as a second step, businesses also utilize social media as a means for internal communication, in which they must utilize the tools that best match specific business purposes [38]. When businesses display to customers through social media that they are working together well-functioning, effective teams, they can enhance the perception of authenticity, their responsiveness to customers, and gain respect from consumers; this reputation will create a competitive advantage in a highly competitive, digital market [38]. The use of social media will additionally increase the ability of creating connections and therefore foster relationship formation [32]; these relationships can transfer between online and offline and lead to gathering attention for issues or creating solutions on different levels of society.

Third is the integration of web 2.0 technologies into the e-commerce strategy, which is perceived as another obstacle for businesses in adopting social media [38]. It is suggested that businesses create communities with consumers in order to keep them engaged with the company and other users [38]. Social media has led to a democratization of participation, which enables users' equal participation in issues or debates on different topics [32]. When creating communities in the interest of businesses that aim to engage consumers in their 
brand, the use of tools such as customer rating platforms, encouraging online word of mouth, letting consumers co-shop with those in their social network, and user-generated cross selling are beneficial [38].

Fourth, businesses must start using the tools to become a social business by adapting to new business models offered through the formation of new web 2.0 technologies [38]. This is based on the idea that social media offers the option of collective customization of content to provide the outcomes most relevant to the recipients [38]. These tools are aimed to assist the user and make the decision-making process easier, e.g., through offering platforms for comparing products or the distribution of valuable user-generated content [38].

The fifth and final step is the evaluation of re-engineered business processes [38]. Social media disrupts traditional business practices, empowering consumers and enhancing their influence [32,38]. This way, businesses must continuously monitor and analyze trends that are portrayed in consumer behavior in order to make decisions according to these outcomes on how to innovate the current strategy [38].

\subsection{The Management of Brand Equity on Social Media}

Aaker [40] (p. 44) defines brand equity as: "a set of brand assets and liabilities linked to a brand, its name and symbol that add to or subtract from the value provided by a product or service". The Brand Equity model by Aaker (1991) consists of five brand assets that together form brand equity: brand loyalty, brand awareness, perceived quality, brand associations, and other proprietary brand assets [40]. Keller [41] (p. 8) later defined brand equity as "the differential effect of brand knowledge on consumer response to the marketing of the brand", in which brand knowledge consists of two dimensions: brand awareness and brand image. These factors help attract new customers, reminding them of products or services, and creating an emotional brand connection [42]. The overall quality of the brand relationship also positively influences the likelihood of brand engagement in terms of willingness to purchase, the intention to remain a member of a specific group, and the intention to create electronic word of mouth [43].

According to Keller (1993), the management of brand equity consists of a six steps process (Figure 3) [41]. First, marketers need to determine the directions and goals for all marketing activities to effectively enhance consumers' brand knowledge. Second, marketers need to decide what image they want to portray in the minds of consumers. Bruhn et al. (2012) differentiate between two types of brand image: functional brand image (based on specific attributes of a product or service) and hedonic brand image (unrelated to attributes of a product or service) [44]. Social media content created by businesses has been shown to positively influence brand awareness and functional brand image, whereas usergenerated content positively influences the hedonic brand image [44]. Third, marketers should consider the possible strategic options to create value in the mind of consumers [41]. The creation and integration of value in all business activities is an important basis for further development of a SMM strategy [24]. An increase in time spent on social media and interactions with the brand positively influence brand awareness, which then influences customer value [45]. If value creation is executed correctly, SMM has been shown to positively influence brand equity and its two dimensions: brand awareness and brand image [46,47]. Customer responses are positively affected by brand equity and investing in brand equity also positively affects the outcomes of SMM activities [46]. Fourth, marketers must create strategies with a long-term vision, especially in the context of brand equity, where brand awareness and brand image change based on earlier marketing activities [41]. Fifth, continuously measuring consumer knowledge to detect changes and whether these are related to the effectiveness of current marketing activities is of high importance. As users are already spending time on social media, businesses must apply the knowledge they gather about customers through social media to their SMM strategy in order to create positive brand equity among a desired target group [10]. Lastly, marketers should assess feasible extension prospects for profitability and potential brand image feedback [41]. 


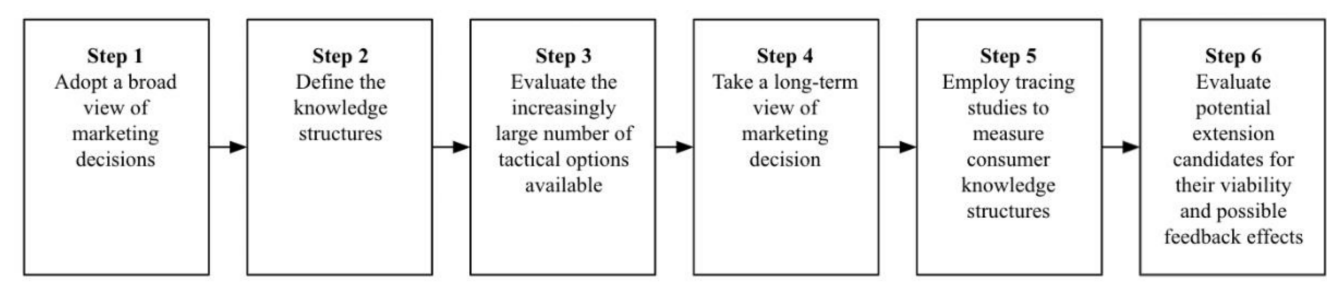

Figure 3. The six general guidelines to manage customer-based brand equity, as visualized by Keller (1993).

\subsection{The Effect of COVID-19 on Consumer Behavior and Businesses}

The COVID-19 pandemic has caused e-commerce to grow substantially, as many consumers continue to shop online [47]. Businesses have experienced substantial growth in their online customer base since the start of the pandemic, of which the markets with existing high conversion rates continue to grow [48]. This sudden adversity towards shopping in physical stores might be caused by cognitive responses to the COVID-19 pandemic, i.e., fear and hope [8]. These factors have been found to mediate the relationship between a consumer's ability to cognitively assess the threat and their behavior [8]; hence, those who experience high levels of fear and perceive the situation to be very threatening will stay home and do their shopping online. Although many consumers indicate that they will most likely continue to shop online, even after stores reopen [49,50], consumer who prefer shopping in physical stores are also forced to adapt to online shopping [10]. This change in consumer behavior is quite demanding for businesses, as they must turn to new methods to reach and engage with all consumers shopping online [50]. When examining the adaptability of consumers to new ways of buying during a pandemic, research shows that increased consumer adaptability weakens consumer resilience and enhances purchase satisfaction [51]. Wang et al. (2020) highlight that a business should make marketing decisions based on the characteristics of that business to find what strategy is most appropriate and beneficial [52]. However, although it is very important to quickly adapt to short-term changes, it is also valuable to look at the long-term effects on the economy, as the future of businesses remains unclear [49].

\section{Methodology}

The research question presented in the introduction will be addressed through a systematic literature review, creating also the opportunity to identify research gaps in literature and simultaneously offer potential explanations to generate new knowledge, clear up any inconsistencies, or develop a conceptual framework by synthesizing existing knowledge [52]. Moreover, a literature review allows for the formulation of future research paths [52] which is especially valuable in this context, where knowledge regarding a specific topic is inadequate, yet literature related to the topic is available [53]. A literature review possesses many advantages over narrative reviews, as they are unbiased, objective, efficient, transparent, reproducible, and rigorous [54]. Systematic literature reviews can be classed as either domain-based, theory-based, and method-based [55]. Domain-based reviews examine, synthesize, and expand on a body of knowledge in a certain domain, while theory-based reviews examine the role of a specific theory in a given field, and a method-based review analyses literature that utilizes an underlying methodology to come to a conclusion [56]. This literature review is classified as a domain-based review in which the approach is aimed at theory development, i.e., the conceptual framework [57]. Utilizing a framework synthesis approach, existing literature is analyzed to discover key constructs and develop a conceptual framework based on prevalent themes and new developments [58-60]. This high-structured approach will produce large amounts of data that are organized and analyzed through identifying key concepts and stakeholders that are relevant in the development of SMM and the role of brand equity during the COVID-19 pandemic [61]. Constructs derived from literature offer the opportunity to explore new developments and utilize this knowledge to create new constructs [59]. 


\subsection{Search Protocol}

\subsubsection{Article Search Process}

Scopus, Semantic Scholar and Google Scholar were utilized to collect literature. For Scopus, the following search $\log$ was used to search and select articles: (("digital market" OR "online market*" OR "social media market") AND ("brand equity" OR "brand value" OR "brand image" OR "brand awareness"))) AND (LIMIT-TO (DOCTYPE, "ar") OR LIMITTO (DOCTYPE, "cp") OR LIMIT-TO (DOCTYPE, "re")) AND (LIMIT-TO (PUBYEAR, 2021) OR LIMIT-TO (PUBYEAR, 2020) OR LIMIT-TO (PUBYEAR, 2019). This search log was only in accordance with the search protocol of Scopus. As this review includes literature over the span of a few years and to not disregard any relevant papers, literature from Google Scholar and Semantic Scholar is also included. As these search engines do not use the same search operators, the prior search log could not have been used here. Therefore, in order to find relevant literature in these databases, the following key terms were used: "social media marketing" AND "brand equity" AND "covid-19" filetype:pdf. As the inclusion criteria state that all articles need to be openly available, "filetype:pdf" has been added to guarantee only the results that were openly available and had a PDF document attached were included.

\subsubsection{Inclusion Criteria}

The search protocol of this systematic literature review consists of the following inclusion criteria: the literature sample may only include (1) journal publications, (2) articles, (3) reviews, (4) theses, or (5) conference papers in (6) English. The literature must have been published in 2019 or later (7) and literature is only included if aimed at explaining terminology or phenomena relevant to brand equity, SMM, or the COVID-19 pandemic (8). Lastly, (9) only literature from Scopus, Semantic Scholar, and Google Scholar will be included that is openly accessible or accessible through the license of the University of Twente.

\subsubsection{Exclusion Criteria}

Literature that is not directly related to developments in SMM, brand equity or the COVID-19 pandemic will be excluded from this literature review. Articles that are not directly written in the context of the current COVID-19 pandemic will not be automatically excluded but will be critically evaluated for their possible contribution to the development of the conceptual framework. As this review is written in English, literature written in other languages will not be included in the sample.

\subsection{Literature Selection}

The literature search resulted in a sample of $\mathrm{N}=21$ from Semantic Scholar $(\mathrm{N}=8)$, Scopus $(\mathrm{N}=7)$ and Google Scholar $(\mathrm{N}=6)$. The process of the literature search is visualized in Figure 4. This figure first visualizes the sample size collected from each source followed by the sample sizes that remained after excluding literature based on the title and the abstract. Although the initial literature search offered many feasible results, only a limited sample remains. This is due to the fact that many results mainly focused on the effects of SMM on brand equity or brand equity as the mediating variable on a specific relationship. Therefore, to make sure that this review will not deviate too much from the initial topic, only articles strongly related to the developments in the field of SMM and COVID-19 in relation to brand equity were included. 


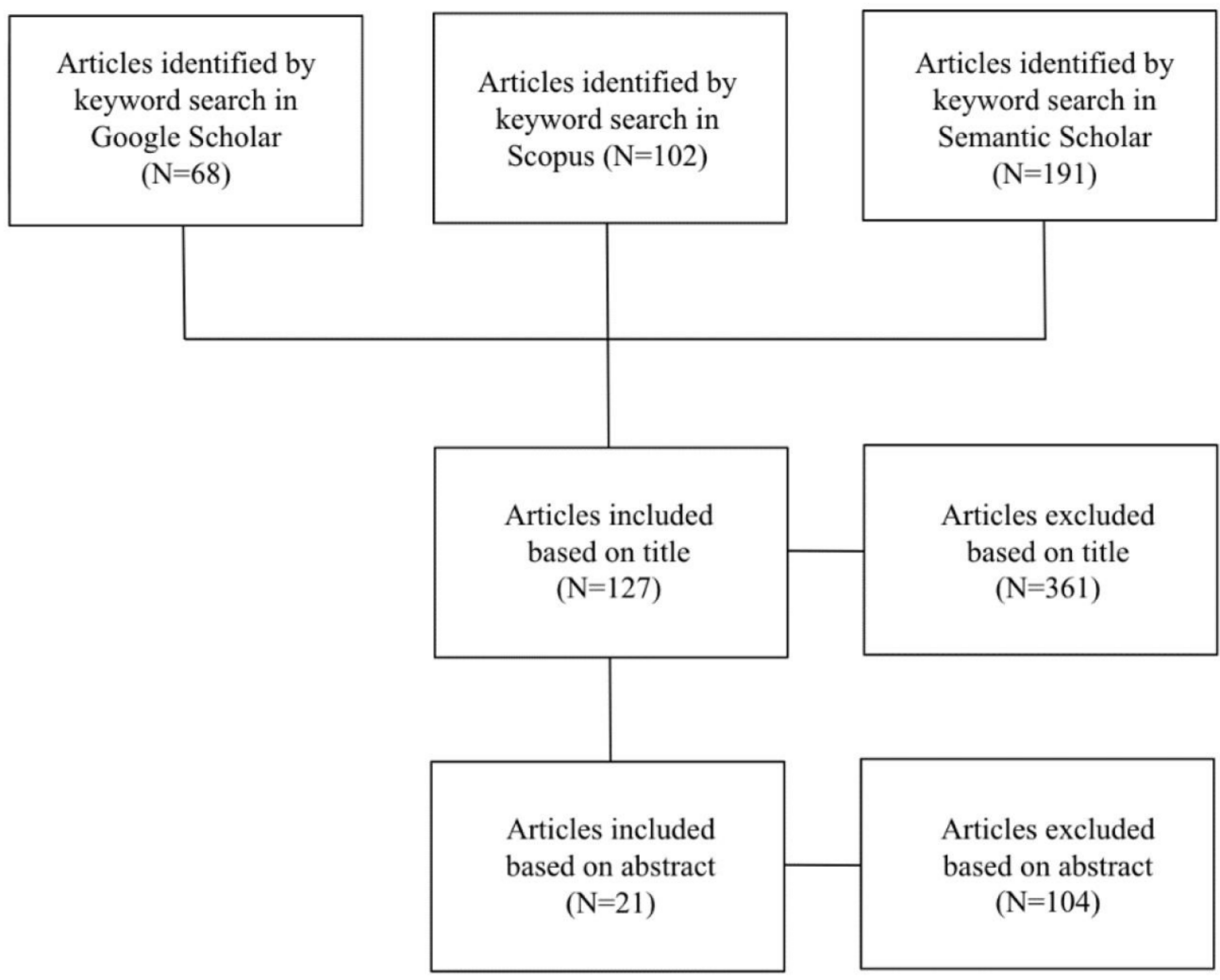

Figure 4. Diagram visualizing the literature search and data collection.

\section{Results}

\subsection{Descriptive Analysis}

The total sample consisted of twenty-one articles, theses, and conference papers. Different categories have been identified in the results provided by the sample and the results have therefore been categorized in different developments or stakeholders relevant to the topic. Table 1 contains the distribution of the articles per specified category. Some provided insights into multiple categories and are therefore included in multiple categories. Table 2 contains more information on the origin of the papers and their significance within the field to give insight into the sample distribution.

Table 1. Categories derived from the collected literature.

\begin{tabular}{cc}
\hline Category or Stakeholder & Authors Referring to the Topic \\
\hline Brand equity and consumer behavior & {$[13,61-74]$} \\
\hline Work performance & {$[13,69,75-78]$} \\
\hline Adoption of technologies & {$[62,73,75,76,79]$} \\
\hline Marketing and management (i.e., businesses) & {$[13,64,67-75,77]$} \\
\hline Government and financial institutions & {$[73,75,77-79]$} \\
\hline Influencers & {$[64,74,76,80]$} \\
\hline $\begin{array}{c}\text { Consumers, Electronic Word-of-Mouth } \\
\text { (eWOM), and customer engagement }\end{array}$ & {$[13,62,65,68-73,75-77]$} \\
\hline Future & {$[13,77,78]$} \\
\hline
\end{tabular}


Table 2. Origins and significance of the literature.

\begin{tabular}{|c|c|c|c|}
\hline Authors & Format & Source & Number of Citations \\
\hline [79] & Journal article & Semantic Scholar & 7 \\
\hline$[61]$ & Journal article & Semantic Scholar & 0 \\
\hline$[62]$ & Journal article & Semantic Scholar & 5 \\
\hline [80] & Journal article & Semantic Scholar & 1 \\
\hline [63] & Journal article & Semantic Scholar & 69 \\
\hline [64] & Journal article & Semantic Scholar & 1 \\
\hline [75] & Journal article & Semantic Scholar & 11 \\
\hline [65] & Journal article & Semantic Scholar & 9 \\
\hline [66] & Journal article & Google Scholar & 0 \\
\hline [76] & Journal article & Google Scholar & 0 \\
\hline [74] & Book & Google Scholar & 0 \\
\hline [77] & Thesis & Google Scholar & 0 \\
\hline [67] & Journal article & Google Scholar & 0 \\
\hline [78] & Journal article & Google Scholar & 8 \\
\hline$[68]$ & Journal article & Scopus & 10 \\
\hline [13] & Journal article & Scopus & 18 \\
\hline [69] & Journal article & Scopus & 6 \\
\hline [70] & Conference paper & Scopus & 0 \\
\hline [71] & Conference paper & Scopus & 0 \\
\hline [72] & Journal article & Scopus & 8 \\
\hline [73] & Journal article & Scopus & 62 \\
\hline
\end{tabular}

\subsection{Thematic Analysis}

This analysis will first describe the role of brand equity in SMM. Then, relevant stakeholders and their role in the creation of brand equity through SMM in times of the COVID-19 pandemic will be elaborated on further. Based on these results, a four-step conceptual framework will be created that can assist businesses in setting up a strategy to create brand equity through SMM.

\subsubsection{The Importance or Brand Equity in Social Media Marketing during a Pandemic}

As discussed, the creation of the perceived brand value among customers is very important. Today's brand value functions as a prediction of the future business earnings [13]. SMM affects brand image which, in turn, creates trust [71]. Trust is an essential element in SMM, as different aspects of the online transaction process can be perceived as complex and diverse which can lead to dishonesty and uncertain behavior from sellers [71]. Building a trustable brand is fruitful in the sense that it enhances brand image, which indirectly increases consumer purchase intentions [71]. Literature shows that SMM positively influences brand equity and has advantages over traditional media when it comes to influencing purchase intention and creating relationships with customers and other corporations $[61,62]$. It has been shown that social media is an influential factor in different stages of the decision-making process, from gathering information to actual purchase behavior [78]. When individuals are highly involved, elements such as advertising value, brand awareness and the impact of the advertisement on purchase intention will be much stronger. Different aspects of social media, i.e., online conversations, brand-related content, easy accessibility, and credibility have been proven to also positively influence brand 
equity [61] and interactions positively influence the five assets of brand equity, resulting in customer response [65].

The first factor, brand loyalty, is positively influenced by activation processing, customer involvement and participation, and the self-expressiveness of a brand [63]. Selfexpressive brands that actively involve customers with content on a brands' page positively influences cognitive information processing and affection for the brand, where consumer participation also creates activation [63]. The second factor, brand awareness, is positively influenced by social media engagement $[65,68]$. Businesses should therefore focus on creating engagement through sharing content related to the brand and its products. Brand awareness has been found to positively influence the third factor of brand equity, perceived quality [63]. The fourth factor, brand associations, has been shown to positively affect brand awareness [68]. Brand associations also influence brand interactions among a specific target audience when the content in question is aimed at that audience [59]. Those who are associated with a brand or product because of intensive and efficient SMM activities are also linked to higher purchase intentions [72]. Different assets of brand equity also have been found to influence each other in the context of SMM in creating trust and customer experiences [68,78].

Overall, investing in the creation and enhancement of brand equity through SMM can result in a positive consumer response, i.e., the willingness to pay more and an increase in brand loyalty [65]. In general, digital marketing has been shown to have a positive effect on purchase intention, in which the perceived value of a brand is a central mediator [66]. However, a strategy on brand creation is required to optimally make use of SMM to create brand equity [13]. This can be done by combining strategy, creativity, and technology, in order to gain a perspective of the customers linked to a specific brand [73]. In order to create positive brand value through technology, brands should utilize data provided by users to create optimal personalized experiences [72]. Customers have the power to either create or destroy brand value through their purchasing behavior, the influencing of others, knowledge development, and co-creation in collaboration with brands [73]. This power can be utilized by businesses to create creative and valuable content and encourage customer interactions or content generation. Through knowledge, expertise, extensive research and continuously gathering feedback, a strategy can be built that offers competitive advantages and gives insights into the manner in which the business should manage SMM [13]. Next to this process, businesses should continuously measure brand valuation among customers to determine the financial value offered by the brand value [13]. Applying these steps to SMM is very feasible, as social media engagement results in an increased business performance [69].

\subsubsection{The Stakeholders in Shaping Social Media Marketing during COVID-19 Government and Financial Institutions}

First, governmental and financial institutions have been identified as those who can encourage capitalization on a national level, granting loans to reduce costs, and develop policies to encourage and assist the use of SMM by businesses [68,75,79]. When businesses perceive and observe the advantages of digital channels as being feasible and the technologies as easy to use, they will be more likely to adopt them [75]. Adopting SMM increases company performance and offers advantages in communication [75]. Those in charge of implementing policies should therefore also offer facilities for the adoption of related technologies and the encouragement of building digital infrastructure as SMM shows to be more feasible in times of the pandemic [75,77].

\section{Businesses}

The rapid adoption of SMM and related technologies are a necessity for businesses aiming to survive or even benefit from the pandemic, as this positively influences brand performance $[74,75,80]$. Digitalization and the pandemic enhance the importance of adapting corporate communication to digital channels to increase consumer trust and brand 
awareness [62,74]. This can be done through creating brand communities and digital marketing campaigns [62], creating the ability to uncover trends in consumer behavior and company performance in real time through the analysis of the content [76]. It is additionally feasible for businesses to adopt new technologies, e.g., artificial intelligence or augmented reality, to not only monitor and optimize marketing campaigns in real time, but also encourage customer engagement [73]. However, this must be handled ethically as to not dehumanize the customer experience, leading to decreasing trust [73].

\section{Social Media Influencers}

Social media influencers were also identified as a stakeholder that can enhance value for businesses during the pandemic [76]. Social media content consists of three different fundamentals: value-adding, self-promotion, and interaction [55]. Influencers offer valuable outcomes in all fundamentals. Firstly, influencers have a value-adding role as a trusted source of information about products and ideas in the mind of consumers $[74,77]$. As consumers are provided with large amounts of information related to the pandemic, they question whom to trust. Secondly, influencers have the role as a promoter of both businesses and themselves as personal brands through covert marketing [74,80]. Thirdly, they also possess the role of interactor between brands and consumers as they both create and consume content [74]. However, the pandemic also creates some challenges for influencers [74]. First are businesses' reduced marketing budgets due to the pandemic, leading to the choice to not to work with influencers. Second is the shift in consumer behavior, where consumers use social media to gather information and connect with others instead of engaging with brands. Therefore, they do not pay attention to the content of influencers about factors that are not linked to the current situation.

\section{Consumers}

The last stakeholders are consumers, who form an essential element in creating and measuring brand equity $[62,68]$. The biggest role that consumers can have both for businesses and other consumers is the generation Electronic Word-of-Mouth (eWOM) and interactions between brands and customers, forming a two-way correspondence [62,76]. Between firm-generated and user-generated content, user-generated content positively influences all aspects of brand equity, trust, reliability, and credibility whereas firm-generated content only impacts brand awareness and brand associations [72]. The creation of e-WOM is beneficial for businesses as they gain insights into consumers' needs, preferences, and views regarding the business and their products, but also offers the possibility to create new business contacts and enhance consumer experience $[73,75,76]$. In addition, engagement enhances the overall rating of a brand [68], leading to increased customer service, creation of interactions between consumers, and sharing of brand stories which might increase the spread of more positive content about the business [68,71,76,77].

\subsubsection{The Management of Social Media during the COVID-19 Pandemic}

Businesses need to have a long-term vision on handling the pandemic and its aftermath by making decisions based on recovery [77]. To survive possible future pandemics or recessions, the creation of savings, education, product or service diversity, and the strategic use of digital marketing are perceived as being of importance [77]. Social media in specific proves to be an essential element in connecting with customers and gaining a competitive advantage. Based on the literature, a conceptual framework has been developed consisting of a four-step SMM strategy to assist businesses in optimizing their social media channels (Figure 5). Per step, relevant stakeholders that have been identified earlier are also included, as they have been shown to contribute to the development or elaboration of the strategy. The results regarding the role of brand equity show that brand equity is mostly created through engaging with consumers, which results in feasible outcomes for the business, i.e., increasing trust and purchase intention and assets of brand equity positively influencing other assets. 


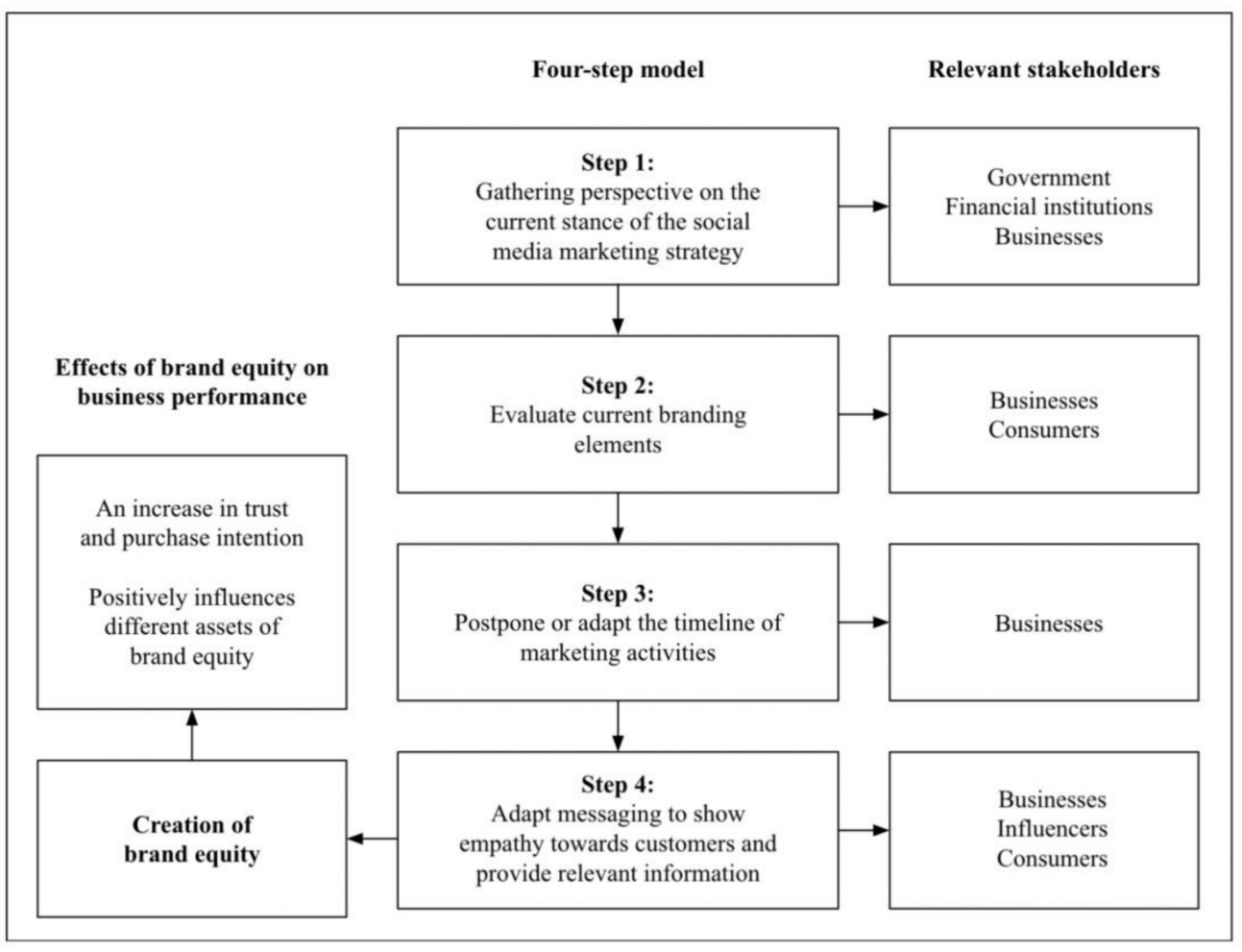

Figure 5. The visualization of the conceptual framework as a long-term SMM strategy to create brand equity.

\subsubsection{The Conceptual Framework as a Long-Term SMM Strategy to Create Brand Equity}

First, businesses should gain perspective of the current stance of their SMM strategy in order to take active steps in the future [77]. Businesses must take into account the change in consumers' expectations as they now expect smooth, integrated and holistic experiences [73]. Within this process, social media is a feasible tool to create an understanding of customers' views, competition, and increase international business contacts [75]. This implies that SMM must be an even more integrated part of the marketing strategy than it currently is. A more comprehensive understanding of customer engagement behavior offers can develop greater value when utilizing social media platforms as part of the marketing strategy [73].

Second, businesses should evaluate their current branding elements and give priority to approaches and channels that attract most consumers [77]. Marketers should adapt these elements to the current situation or other influential external factors with the attitudes of customers regarding their product in mind and present products and services with empathy and transparency [78]. In this situation, social media can be utilized to grow one's reach by sharing the adapted brand elements, i.e., advertising, to create a salient brand image and enhance brand equity [64]. These brand elements are also a representation of the brand image [70]. To effectively make use of social media, businesses should choose the social media platforms with the most potential for their business, evaluate the effectiveness of all platforms through different tools to gather feasible insights, and understand the impact of these platforms on business performance [69]. Based on these results, businesses should increase customer activation levels, strengthen the bond with consumers to gather insights into their needs, interests, and values, and use this to create interactive experiences and involve them through content [63].

Third, marketers must postpone or adapt the timeline of their planned marketing activities depending on the situation the business is in [77]. In addition, businesses should also integrate a periodic evaluation of brand value levels as a new business practice to identify points of improvement and create adequate strategies to further increase brand 
value $[13,68]$. The role of the brand, trust and reputation are increasing in importance and maximizing the perceived brand value positively influences consumer preferences and choices $[13,68,71]$. Due to the increase in the use of digital channels and technologies and thus in knowledge of these elements, consumers are better prepared, more aware, and critical when it comes to technologies and brands [13].

Fourth, businesses should rapidly adapt their messaging to show empathy towards their customers and provide relevant information regarding consumer purchases and measures the business is taking to keep both employees and customers safe $[13,77,78]$. Next, brands should also implement new ways in which they can sell products and deliver services [78]. Brand awareness, brand image, brand experience, customer trust, and consumer satisfaction created through social media have been shown to positively affect purchase decisions, showing that a social media strategy can assist consumers in the decision-making process but also offer them support or information $[71,77,78]$. In addition, the brand should be associated with elements perceived as good [78]. Firmgenerated content, e.g., product videos, brand fan content, and user-generated content have been found to positively influence the creation of brand passion [72]. Marketers have the role of communicator and promoter in effectively transmitting messages and gathering positive feedback from customers [70]. A challenge within this step might be the increasing expectations among both employees and customers regarding the manner in which a business contributes to environmental and societal causes [13]. Literature also proposes that businesses might be more sustainable post-crisis when adapting to business models built on being environmentally aware [73].

\section{Conclusions}

This systematic literature review aimed to provide an answer to the question how businesses can adapt their SMM to the effects caused by the pandemic to create positive brand equity. The literature analysis showed that a long-term vision will create the most beneficial outcomes during and after the pandemic. From the literature, a four-step conceptual framework including relevant stakeholders was identified. First, businesses should gather a clear perspective of their current SMM strategy before taking additional steps in improving the strategy. In this process, governmental parties and financial institutions can also get involved as they can provide businesses with options, e.g., funding, to adopt SMM. Second, the evaluation of current branding elements and adapting them to the situation is of importance. In this process, the attitudes, needs, and wishes of customers play an essential role and are therefore considered an important stakeholder. Third, based on the perspective, branding, and situation, businesses must either adapt or postpone marketing activities. Brand equity proves to be an essential element in influencing consumer behavior and decision-making. Therefore, brand equity should be evaluated periodically to identify points of improvement. Fourth, communication and engaging with consumers is of high importance to provide relevant information and grow brand equity, e.g., through product related content, influencers, and firm-generated and user-generated content to enhance the customer experience. User-generated content offers many benefits to both businesses and consumers as it helps in understanding what (other) customers think, informing and supporting, and influencing consumer decision-making behavior. However, it should be noted that these results functions as a first insight into the manner in which the COVID-19 pandemic has changed the SMM sphere. The conceptual framework visualizes what is currently known about the effect of the pandemic on SMM and what changes are likely to occur in the future. In order to make more substantial claims regarding these factors, it is of importance that additional research is performed in this domain or this literature review is replicated containing literature from a larger timeframe.

When taking a closer look at the developments that have emerged during the pandemic, there are some developments that are worth noting in order to create an understanding of the future of SMM. First is the increasing influence of digital technologies on business practices. As noted in both the theoretical framework and the findings of this 
literature review, technologies are developing at a rapid pace and businesses need to adapt to and keep up with these developments in order to offer optimal solutions to consumers. Research has shown that young consumers buy online more often, making up a large share of the total number of e-retail consumers. Additionally, they are more often buying through social media, where they are more attentive to products that are less impactful on the environment. This is in line with our results, indicating that consumers are increasingly more interested in conscious consumption and therefore make decisions accordingly. This implies that businesses must focus on creating conscious products and enhancing brand equity through online channels, as they have to communicate with consumers and connect them to their brand. Although nothing can be concluded for sure, it is apparent that many businesses that have converted to online channels during the pandemic will, to some extent, stay online or even expand their current online market share in order to stay connected with consumers.

Additionally, the second development that has gained the interest and relevance in both academics and practice is the role of the consumer. As described in our theoretical framework, the social media consumer nowadays can be described as empowered and influential in the social media environment. In pre-pandemic times, businesses could perhaps still get away with not paying sufficient attention to the online discourse taking place among consumers and their behavior because of this discourse. However, amidst the COVID-19 pandemic, the trend of consumers being active and influential actors in the decision-making process has persisted. This development is especially relevant in the context of social media, as these platforms have been designed for consumers to connect and communicate and businesses are viewed as uninvited to this online discourse.

In relation to this, a third development refers to the need of businesses to connect with consumers through their values and thus emphasizing the need of creating brand equity through social media in order to connect the consumer to the brand. This indicates that businesses must speak up and deliver positive contributions to causes that matter to the consumer. The consumer votes through his wallet and this is increasingly clear in times of the pandemic, seeing that the influence of consumers on social media platforms has grown to where social media has become a space for consumers to interact and discuss brands and businesses attempting to advertise their brand are perceived as unwelcome. Combined with the growing e-retail market leading to increased competitiveness between businesses online, the importance of generating positive brand equity to create the favorable attitudes in the mind of consumers increases. Additionally, the consumer has become more aware of the effects of their consumption behavior on the environment. As a consequence of this, businesses have to make sure that they adhere to this and stand out from others by creating sustainable products or services that reduce the impact on society in addition to creating brand equity.

However, not only the influence of the consumer is expected to grow in the future, but other parties are also indicated to benefit from the current and possible future changes. As the e-retail market continues to grow and businesses are increasingly investing in optimizing their online channels, parties that can provide businesses with financial aid are also expected to play a larger role in the future of e-retail. These parties, i.e., governmental and financial parties, can help businesses build and strengthen their digital channels by investing in the optimization of these channels, creating valuable opportunities for both parties. As the value of the e-retail market is growing, businesses that are not yet adjusted to the demands of the digital sphere have more opportunities to reach the modern, online consumer. Governmental and financial parties can invest in these businesses to gain long-term revenue when these businesses prove to be successful.

As mentioned, the increasing competitiveness on digital markets during the pandemic has put an even greater emphasis on positioning the business to effectively differentiate them from competition. Mostly during the pandemic, creating brand equity forms the basis for creating developments such as brand loyalty, awareness, and trust among consumers. It remains unclear what the exact role of brand equity will be in the future of social 
media marketing but seeing that the impact of digitalization and consumers on business practices will likely continue, brand equity remains an important facet of the future of SMM strategies.

\section{Limitations}

This review has a few limitations which should be considered. First, this study was based on a very limited sample size consisting of very recent publications. Therefore, the conceptual framework can only be considered as a basis for further research and does not function as a completely accurate representation of all data available. Second, there is not much literature available on the long-term effects of the pandemic on economies, businesses and consumer behavior. Therefore, creating a long-term strategy is rather difficult and more data and research is needed to extend the conceptual framework. Third, no specific distinction has been made regarding countries, consumer types, or the level of technology integration. Hence, it is unclear whether the functionality of the conceptual framework is affected by the country it is implemented in, specific customer types or the ease in which the target audience can make use of technologies. In order to determine this, the framework should be empirically tested in different contexts. The final limitation is the timeframe from which the literature was selected. As the COVID-19 pandemic first appeared in late 2019 and is still prevalent in 2021, the choice was deliberately made to only select articles from this timeframe. This choice, although earlier research might have provided this study with some more detailed and elaborate insights, the choice to not include it was made in order to not divert from the original objective of discovering changes and opportunities unique to the context of COVID-19 and how these changes and opportunities will shape the current and future SMM sphere. Additionally, it prevents the formation of a biased approach as not much is known how this unique situation affects SMM. It is recommended that, if replicated, future research includes a larger timeframe in their methodology as to possibly elaborate further on the results found in this review.

\section{Future Research}

This review has shown some areas which still need to be explored further before a definitive SMM strategy can be defined. First, the conceptual framework should be empirically tested in order to determine its validity and reliability. Further research can also uncover some new aspects that were not included or discovered in the literature of this research and further develop the conceptual framework.

To extent the conceptual framework and build upon the results of this study, literature from a longer time period should be included. This will give a more elaborate insight into the manner in which the SMM sphere and e-commerce as a whole were already developing prior to the COVID-19 pandemic and how this has affected the manner in which businesses adapted to the changes brought by the pandemic. This includes a comparison of pre- and post-pandemic data and literature where not only the domain of SMM, but also consumer behavior, e-commerce, and technical developments are included and their possibly moderating effects are analyzed. When more is known about current and past long-term developments, better predictions can be made about the future and a strategy can be developed accordingly.

This should be combined with further research into the way in which different stakeholders influence the future of SMM and how it shapes the creation of brand equity. Within the process of creating brand equity, literature emphasized that consumer expectations are increasing, along with their influence. Therefore, the future role of consumers and the identified stakeholders in the creation of brand equity should be further researched to determine how their influence will shift and what effects this will have.

\section{Theoretical Relevance}

This review is relevant for academics as it provides exploratory insights into the way in which future SMM strategies need to be shaped and who important stakeholders 
are. By building on different studies related to the topic, an exploratory overview of different steps to create a long-term SMM strategy has been defined. As our research has focused on literature that was released during the COVID-19 pandemic, this will bring some new insights that possibly could not have been considered in earlier research as these changes did not exist yet. The results from this research form an addition to changes and developments that were already taking place before the COVID-19 pandemic. Together, this can assist academics in making more accurate and elaborate predictions on how factors such as new technologies and changing consumer behavior will shape the SMM sphere. Academics can use and empirically test the framework provided in this research to further research the ways in which COVID-19 has affected marketing strategies so far and what developments are here to stay or further shape the field.

\section{Practical Relevance}

This review also is of practical relevance, as it was introduced at the beginning of this review that many businesses struggle to create brand equity through SMM. This review can assist businesses in setting up a SMM strategy with a long-term vision to connect with consumers and create brand equity. This research should be viewed as an addition on the current SMM strategy and assist businesses in adjusting their strategy to accommodate the consumers that have adopted and prefer online shopping but also those who prefer physical shopping but are required to adopt online channels as the possibilities of going to physical stores is limited. These insights are also relevant for other stakeholders identified in this review, i.e., governmental parties, financial institutions, and influencers, as they can assist businesses in making optimal use of the possibilities offered by SMM and benefit from it themselves.

Funding: This research received no external funding.

Institutional Review Board Statement: Not applicable.

Informed Consent Statement: Not applicable.

Data Availability Statement: Not applicable.

Conflicts of Interest: The authors declare no conflict of interest.

\section{References}

1. Donthu, N.; Gustafsson, A. Effects of COVID-19 on business and research. J. Bus. Res. 2020, 117, 284-289. [CrossRef]

2. eMarketer. Available online: https://www.emarketer.com/chart/242908/retail-ecommerce-sales-worldwide-2019-2024-trillionschange-of-total-retail-sales (accessed on 2 September 2021).

3. Garrido-Moreno, A.; García-Morales, V.; King, S.; Lockett, N. Social Media use and value creation in the digital landscape: A dynamic-capabilities perspective. J. Serv. Manag. 2020, 31, 313-343. [CrossRef]

4. Eisenhardt, K.M.; Martin, J.A. Dynamic Capabilities: What Are They? Strat. Manag. J. 2000, 21, 1105-1121. [CrossRef]

5. Seetharaman, P. Business models shifts: Impact of Covid-19. Int. J. Inf. Manag. 2020, 54, 102173. [CrossRef]

6. Mason, A.N.; Narcum, J.; Mason, K. Social media marketing gains importance after Covid-19. Cogent Bus. Manag. $2021,8,1870797$. [CrossRef]

7. Shopify. Future of Commerce. 2021, pp. 1-32. Available online: https://cdn.shopify.com/static/future-of-commerce/Shopify\% 20Future\%20of\%20Commerce\%202021.pdf (accessed on 2 September 2021).

8. Kim, J.; Yang, K.; Min, J.; White, B. Hope, fear, and consumer behavioral change amid COVID-19: Application of protection motivation theory. Int. J. Consum. Stud. 2021, 1-17. [CrossRef]

9. Sheth, J. Impact of Covid-19 on consumer behavior: Will the old habits return or die? J. Bus. Res. 2020, 117, 280-283. [CrossRef] [PubMed]

10. Evans, D.; McKee, J.; Bratton, S. Social Media Marketing: The Next Generation of Business Engagement; Wiley: Hoboken, NJ, USA, 2010.

11. Fournier, S.M.; Avery, J.J. The Uninvited Brand. SSRN Electron. J. 2010, 54, 193-207. [CrossRef]

12. Zahoor, S.Z.; Qureshi, I.H. Social Media Marketing and Brand Equity: A Literature Review. Iup. J. Mark. Manag. 2017, 16, 1-19.

13. Dumitriu, D.; Militaru, G.; Deselnicu, D.C.; Niculescu, A.; Popescu, M.A.M. A Perspective Over Modern SMEs: Managing Brand Equity, Growth and Sustainability Through Digital Marketing Tools and Techniques. Sustainability 2019, 11, 2111. [CrossRef]

14. Kirk, C.P.; Rifkin, L.S. I'll trade you diamonds for toilet paper: Consumer reacting, coping and adapting behaviors in the COVID-19 pandemic. J. Bus. Res. 2020, 117, 124-131. [CrossRef] 
15. Laato, S.; Islam, A.K.M.N.; Farooq, A.; Dhir, A. Unusual purchasing behavior during the early stages of the COVID-19 pandemic: The stimulus-organism-response approach. J. Retail. Consum. Serv. 2020, 57, 102224. [CrossRef]

16. Tønnessen, Ø.; Dhir, A.; Flåten, B.T. Digital knowledge sharing and creative performance: Work from home during the COVID-19 pandemic. Technol. Forecast. Soc. Chang. 2021, 170, 120866. [CrossRef]

17. Khanra, S.; Dhir, A.; Kaur, P.; Joseph, R.P. Factors influencing the adoption postponement of mobile payment services in the hospitality sector during a pandemic. J. Hosp. Tour. Manag. 2021, 46, 26-39. [CrossRef]

18. Sharma, R.; Dhir, A.; Talwar, S.; Kaur, P. Over-ordering and food waste: The use of food delivery apps during a pandemic. Int. J. Hosp. Manag. 2021, 96, 102977. [CrossRef]

19. Ahmed, M.A.; Zahid, Z. Role of social media marketing to enhance CRM and brand equity in terms of purchase intention. Asian J. Manag. Res. 2014, 4, 533-549.

20. Yazdanparast, A.; Joseph, M.; Muniz, F. Consumer based brand equity in the 21st century: An examination of the role of social media marketing. Young Consum. 2016, 17, 243-255. [CrossRef]

21. Zollo, L.; Filieri, R.; Rialti, R.; Yoon, S. Unpacking the relationship between social media marketing and brand equity: The mediating role of consumers' benefits and experience. J. Bus. Res. 2020, 117, 256-267. [CrossRef]

22. Huang, Y.; Yang, S.; Zhu, Q. Brand equity and the Covid-19 stock market crash: Evidence from U.S. listed firms. Financ. Res. Lett. 2021, 101941. [CrossRef]

23. Talwar, S.; Talwar, M.; Tarjanne, V.; Dhir, A. Why retail investors traded equity during the pandemic? An application of artificial neural networks to examine behavioral biases. Psychol. Mark. 2021, 1-22. [CrossRef]

24. Constantinides, E. Foundations of Social Media Marketing. Procedia Soc. Behav. Sci. 2014, 148, 40-57. [CrossRef]

25. Berthon, P.R.; Pitt, L.F.; Plangger, K.; Shapiro, D. Marketing meets Web 2.0, social media, and creative consumers: Implications for international marketing strategy. Bus. Horiz. 2012, 55, 261-271. [CrossRef]

26. Dahnil, M.I.; Marzuki, K.M.; Langgat, J.; Fabeil, N.F. Factors Influencing SMEs Adoption of Social Media Marketing. Procedia Soc. Behav. Sci. 2014, 148, 119-126. [CrossRef]

27. Öztamur, D.; Karakadılar, İ.S. Exploring the role of social media for SMEs: As a new marketing strategy tool for the firm performance perspective. Procedia-Soc. Behav. Sci. 2014, 150, 511-520. [CrossRef]

28. Lin, Y.; Kant, S. Using Social Media for Citizen Participation: Contexts, Empowerment, and Inclusion. Sustainability 2021, $13,6635$. [CrossRef]

29. Frąckiewicz, E. Information and Communication Technologies as a Source of Customer Value in the Context of Balancing the Positions of Younger and Older Consumers. Sustainability 2021, 13, 4722. [CrossRef]

30. Abdallah, S.; Jaleel, B. Website Appeal: Development of an Assessment Tool and Evaluation Framework of E-Marketing. J. Theor. Appl. Electron. Commer. Res. 2015, 10, 45-62. [CrossRef]

31. Hwang, J.; Eves, A.; Stienmetz, J.L. The Impact of Social Media Use on Consumers' Restaurant Consumption Experiences: A Qualitative Study. Sustainability 2021, 13, 6581. [CrossRef]

32. Kozinets, R.V.; Belz, F.M.; McDonagh, P. Social Media for Social Change: A Transformative Consumer Research Perspective, 1st ed.; Routledge: Oxfordshire, UK, 2011.

33. Kietzmann, J.H.; Hermkens, K.; McCarthy, I.P.; Silvestre, B.S. Social media? Get serious! Understanding the functional building blocks of social media. Bus. Horiz. 2011, 54, 241-251. [CrossRef]

34. Dhir, A.; Talwar, S.; Kaur, P.; Budhiraja, S.; Islam, N. The dark side of social media: Stalking, online self-disclosure and problematic sleep. Int. J. Consum. Stud. 2021, 1-19. [CrossRef]

35. Yannopoulou, N.; Liu, M.J.; Bian, X.; Heath, T. Exploring social change through social media: The case of the Facebook group Indignant Citizens. Int. J. Consum. Stud. 2019, 43, 348-357. [CrossRef]

36. Wei, G.; Lin, W.; Yanxiong, W.; Jingdong, Y.; Musse, S.Y. The Relationship of Sustainability Communication on Social Media with Banking Consumers' Loyalty through e-WOM. Sustainability 2021, 13, 3832. [CrossRef]

37. Bui, H.T. Exploring and explaining older consumers' behaviour in the boom of social media. Int. J. Consum. Stud. 2021, 1-20. [CrossRef]

38. Jacobs, A.; Nakata, K. Evolving the social business. First Interdiscip. Workshop Commun. Sustain. Communities 2010, 1-6. [CrossRef]

39. Earl, M.J. Evolving the E-Business. Bus. Strategy Rev. 2000, 11, 33-38. [CrossRef]

40. Aaker, D.A. Managing Brand Equity: Capitalizing on the Value of a Brand Name; The Free Press: New York, NY, USA, 1991.

41. Keller, K.L. Conceptualizing, Measuring, and Managing Customer-Based Brand Equity. J. Mark. 1993, 57, 1-22. [CrossRef]

42. Lemon, K.N.; Rust, R.T.; Zeithaml, V.A. What Drives Customer Equity? Mark. Manag. 2001, 10, $20-25$.

43. Lou, L.; Jiao, Y.; Koh, J. Determinants of Fan Engagement in Social Media-Based Brand Communities: A Brand Relationship Quality Perspective. Sustainability 2021, 13, 6117. [CrossRef]

44. Bruhn, M.; Schoenmueller, V.; Schäfer, D.B. Are social media replacing traditional media in terms of brand equity creation? Manag. Res. Rev. 2012, 35, 770-790. [CrossRef]

45. Stojanovic, I.; Andreu, L.; Curras-Perez, R. Effects of the intensity of use of social media on brand equity. Eur. J. Manag. Bus. Econ. 2018, 27, 83-100. [CrossRef]

46. Godey, B.; Manthiou, A.; Pederzoli, D.; Rokka, J.; Aiello, G.; Donvito, R.; Singh, R. Social media marketing efforts of luxury brands: Influence on brand equity and consumer behavior. J. Bus. Res. 2016, 69, 5833-5841. [CrossRef] 
47. Stanciu, S.; Radu, R.-I.; Sapira, V.; Bratoveanu, B.-D.; Florea, A.-M. Consumer Behavior in Crisis Situations. Research on the Effects of COVID-19 in Romania. Ann. Dunarea Jos Univ. Galati. Fascicle I Econ. Appl. Inform. 2020, 26, 5-13. [CrossRef]

48. Arora, N.; Charm, T.; Grimmelt, A.; Ortega, M.; Robinson, K.; Sexauer, C.; Staack, Y.; Whitehead, S.; Yamakawa, N. A Global View of How Consumer Behavior is Changing Amid COVID-19; McKinsey \& Company: New York, NY, USA, 2020.

49. Roggeveen, A.L.; Sethuraman, R. How the COVID-19 Pandemic May Change the World of Retailing. J. Retail. 2020, 96, 169-171. [CrossRef]

50. Kursan Milaković, I. Purchase experience during the COVID-19 pandemic and social cognitive theory: The relevance of consumer vulnerability, resilience, and adaptability for purchase satisfaction and repurchase. Int. J. Consum. Stud. 2021, 1-18. [CrossRef]

51. Wang, Y.; Hong, A.; Li, X.; Gao, J. Marketing innovations during a global crisis: A study of China firms' response to COVID-19. J. Bus. Res. 2020, 116, 214-220. [CrossRef] [PubMed]

52. Hulland, J.; Houston, M.B. Why systematic review papers and meta-analyses matter: An introduction to the special issue on generalizations in marketing. J. Acad. Mark. Sci. 2020, 48, 351-359. [CrossRef]

53. Petticrew, M.; Roberts, H. Systematic Reviews in the Social Sciences; Blackwell Publishing: Hoboken, NJ, USA, 2006.

54. Lyngdoh, T.; Chefor, E.; Hochstein, B.; Britton, B.P.; Amyx, D. A systematic literature review of negative psychological states and behaviors in sales. J. Bus. Res. 2021, 122, 518-533. [CrossRef]

55. Paul, J.; Criado, A.R. The art of writing literature review: What do we know and what do we need to know? Int. Bus. Rev. 2020, 29, 101717. [CrossRef]

56. Palmatier, R.W.; Houston, M.B.; Hulland, J. Review articles: Purpose, process, and structure. J. Acad. Mark. Sci. 2018, 46, 1-5. [CrossRef]

57. Hong, Q.N.; Pluye, P.; Bujold, M.; Wassef, M. Convergent and sequential synthesis designs: Implications for conducting and reporting systematic reviews of qualitative and quantitative evidence. Syst. Rev. 2017, 6, 1-14. [CrossRef]

58. Xiao, Y.; Watson, M. Guidance on Conducting a Systematic Literature Review. J. Plan. Educ. Res. 2017, 39, 93-112. [CrossRef]

59. Kastner, M.; Tricco, A.C.; Soobiah, C.; Lillie, E.; Perrier, L.; Horsley, T.; Welch, V.; Cogo, E.; Antony, J.; Straus, S.E. What is the most appropriate knowledge synthesis method to conduct a review? Protocol for a scoping review. BMC Med. Res. Methodol. 2012, 12, 1-10. [CrossRef]

60. Barnett-Page, E.; Thomas, J. Methods for the synthesis of qualitative research: A critical review. BMC Med. Res. Methodol. 2009, 9, 1-11. [CrossRef]

61. Riaz, M.H.; Ahmed, M.H.; Akhtar, D.S. The Role of Social Media Marketing on Building Brand Equity (An Insight of Fast Food Industry of Pakistan). Int. J. Engl. Lit. Soc. Sci. 2019, 4, 388-395. [CrossRef]

62. Dissanayake, D.M.R.; Siriwardana, A.; Ismail, N. Social Media Marketing and Customer Engagement: A Review on Concepts and Empirical Contributions. Kelaniya J. Manag. 2019, 8, 71-85. [CrossRef]

63. Algharabat, R.; Rana, N.P.; Alalwan, A.A.; Baabdullah, A.; Gupta, A. Investigating the antecedents of customer brand engagement and consumer-based brand equity in social media. J. Retail. Consum. Serv. 2020, 53, 101767. [CrossRef]

64. Galdeano, D.M.; Fati, M.; Ogalo, H.S.; Abro, Z. Social media and purchase intention: Findings for future empirical directions. Humanit. Soc. Sci. Rev. 2019, 7, 141-150. [CrossRef]

65. Khan, Z.; Yang, Y.; Shafi, M.; Yang, R. Role of Social Media Marketing Activities (SMMAs) in Apparel Brands Customer Response: A Moderated Mediation Analysis. Sustainability 2019, 11, 5167. [CrossRef]

66. Khan, A.S.; Bilal, M.; Saif, M.; Shehzad, M. Impact of Digital Marketing on Online Purchase Intention: Mediating Effect of Brand Equity \& Perceived Value. Inst. Bus. Manag. 2020, 1-50. [CrossRef]

67. Permana, A.W. The Influence of Social Media, Brand Awareness, Brand Image, Brand Experience Through Satisfaction and Trust on Purchase Decisions During The COVID-19 Pandemic. Am. Int. J. Bus. Manag. 2021, 4, 7-15. Available online: http:/ /www.aijbm.com/wp-content/uploads/2021/01/B410815.pdf. (accessed on 6 April 2021).

68. Niculescu, A.; Dumitriu, D.; Purdescu, C.; Popescu, M.A.M. Enhancing Brand Value of Modern Organizations through Digital Marketing Tools and Techniques: A Study on Top Ten Romanian Companies. TEM J. 2019, 8, 171-181. [CrossRef]

69. Li, J.J.; Kim, W.G.; Choi, H.M. Effectiveness of social media marketing on enhancing performance: Evidence from a casual-dining restaurant setting. Tour. Econ. 2019, 27, 3-22. [CrossRef]

70. Wibowo, S.; Hidayat, R.; Suryana, Y.; Sari, D.; Kaltum, U. Measuring the Effect of Advertising Value and Brand Awareness on Purchase Intention through the Flow Experience Method on Facebook's Social Media Marketing Big Data. In Proceedings of the 2020 8th International Conference on Cyber and IT Service Management (CITSM), Pangkal, Indonesia, 23-24 October 2020; pp. 1-5. [CrossRef]

71. Moslehpour, M.; Ismail, T.; Purba, B.I.; Lin, P.K.C. The Effects of Social Media Marketing, Trust, and Brand Image on Consumers' Purchase Intention of GO-JEK in Indonesia. In Proceedings of the 2020 The 6th International Conference on E-Business and Applications, Kuala Lumpur, Malaysia, 25-27 February 2020; pp. 5-10. [CrossRef]

72. Mukherjee, K. Social media marketing and customers' passion for brands. Mark. Intell. Plan. 2019, 38, 509-522. [CrossRef]

73. Dwivedi, Y.K.; Ismagilova, E.; Hughes, D.L.; Carlson, J.; Filieri, R.; Jacobson, J.; Jain, V.; Karjaluoto, H.; Kefi, H.; Krishen, A.S.; et al. Setting the future of digital and social media marketing research: Perspectives and research propositions. Int. J. Inf. Manag. 2020, 102168. [CrossRef]

74. Bunkanwanicha, P.; Coeurderoy, R.; Ben Slimane, S. Managing a Post-Covid19 Era, E-book; ESCP Business School: Paris, France, 2020. 
75. Eid, R.; Abdelmoety, Z.; Agag, G. Antecedents and consequences of social media marketing use: An empirical study of the UK exporting B2B SMEs. J. Bus. Ind. Mark. 2019, 1-50. [CrossRef]

76. Murshed, N.A. How Social Media Changes Today's Marketing Strategies. Int. J. Innov. Res. Growth 2020, 5, 725-736. [CrossRef]

77. Abkenar, S.N. Influence of the economic crisis on SME's marketing. Bachelor's Thesis, Häme University of Applied Sciences, Hämeenlinna, Finland, 2020.

78. Ting, H.; Ling, J.; Cheah, J.H. Editorial: It Will Go Away!? Pandemic Crisis and Business in Asia. Asian J. Bus. Res. 2020, 10, 1-7. [CrossRef]

79. Patma, T.S.; Wardana, L.W.; Wibowo, A.; Narmaditya, B.S. The Shifting of Business Activities during the COVID-19 Pandemic: Does Social Media Marketing Matter? J. Asian Financ. Econ. Bus. 2020, 7, 283-292. [CrossRef]

80. Archer, C.; Wolf, K.; Nalloor, J. Capitalising on chaos-exploring the impact and future of social media influencer engagement during the early stages of a global pandemic. Media Int. Aust. 2020, 178, 106-113. [CrossRef] 